\title{
Illness, disability, and drugs among 25 to 75 year olds living at home
}

\author{
HEDLEY PEACH AND JOHN R H CHARLTON
}

From the Department of Community Medicine, St Thomas's Hospital Medical School, London SE1 7EH

SUMMARY A survey in a London borough showed that $15 \%$ of adults living at home were restricted in one or more areas of their lives because of illness. A sample of these adults aged 25 to 75 years was interviewed using a validated medical questionnaire, and the severity of their restrictions was also assessed using a separate instrument. Many symptoms were found which had not been reported to a doctor and many were not being treated. When the disability scores were regressed on symptoms classified as reported to a doctor, unreported, or absent, with a few exceptions it was the reported symptoms that were significantly associated with disability. Similarly, when symptoms were classified as treated (by doctor or respondent), untreated, or absent, treated symptoms were associated with disability. Some disabling symptoms were similar to the effects, mainly adverse, of commonly prescribed drugs, and these symptoms were reported more frequently by respondents taking the possible offending drug than by those not taking the drug. It appears that making general practitioners aware of unreported and untreated symptoms among their 25 to 75 year old patients will not reduce the overall level of disability in the community. However, the iatrogenic component of disability needs to be studied further.

The World Health Organization's (WHO) international classification of disablement ${ }^{1}$ defines the terms impairment, disability, and handicap and then links them together in a conceptual scheme such that handicap is seen as consequent on disability or impairment, disability as consequent on impairment, and impairment as consequent on disease or disorder, thus:

$$
\begin{aligned}
& \text { Disease } \\
& \text { or } \\
& \text { Disorder }
\end{aligned} \rightarrow \text { Impairment } \rightarrow \text { Disability } \rightarrow \text { Handicap }
$$

The implication of the relation between impairment, disability, and handicap seen by WHO is that disability in a population would be reduced if it were possible to prevent or effectively treat the diseases or impairments that lead to disability.

Many of the items in the WHO classification of impairments are symptoms. Several studies have shown that the general population decides to obtain treatment from their general practitioner or a hospital for only a small proportion of their symptoms, ${ }^{2-5}$ and many of the unreported symptoms are also not being treated by the individuals themselves. ${ }^{4-6}$ Reporting of symptoms to a doctor and self-medication has been said to depend on many factors and not simply the impact of the symptoms on an individual's life (for references see 7). Therefore, it is possible that a large proportion of the general population have symptoms which are restricting their activities (ie, causing disability) ${ }^{1}$ but they have not reported those symptoms to their doctors. If unreported or untreated symptoms are also common among disabled people and such symptoms are associated with activity restrictions it follows that there might be grounds for trying to reduce the level of disability in the community by increasing general practitioners' awareness and treatment of disabling symptoms.

Disabled people are not representative of the general population. They tend to be older; a larger proportion are single and there are very few pregnant women or mothers with dependent children. ${ }^{\mathbf{s}}$ Many are already under their doctor's surveillance ${ }^{9}$ and hence more likely to report other symptoms. Surveys of the disabled have been concerned with the unmet need for welfare services, and the extent to which unrecognised or untreated symptoms occur among a community based sample of disabled people has not been studied specifically. Evidence that unrecognised or untreated symptoms might be encountered quite frequently among disabled people in the community comes directly from screening 
studies of the elderly, a group which contains a large proportion of disabled people. Nearly all of these surveys have reported many unrecognised problems affecting health (for references see 10). Indirect evidence comes from studies on special groups of disabled people, for example, rheumatoid arthritis patients, ${ }^{11}$ epileptics, ${ }^{12}$ or multiple sclerosis patients, ${ }^{13}$ all of which have found under utilisation of health services. Furthermore, a study comparing general practitioners' working knowledge of their disabled patients' problems with information obtained from the patients themselves revealed that general practitioners knew of only a third of the diseases the patients had and only a fifth of the symptoms. ${ }^{14}$

A study being carried out in the London borough of Lambeth gave us the opportunity to explore the extent of unrecognised and untreated symptoms among the disabled and to assess their contribution to the overall level of disability in the community. A postal survey of a random sample of households had identified adults who were restricted in one or more areas of their lives because of disease or disorder. ${ }^{8}$ The screening questionnaire covered the categories of the international classification of disability ${ }^{1}$ more comprehensively than hitherto, and these adults, except the mentally handicapped, the blind, the deaf, and the very elderly (over 75 years old), were interviewed annually over the next three years.

\section{Methods}

A validated medical questionnaire was incorporated into the second interview during which the severity of disability was assessed by means of a separate detailed questionnaire.

MEDICAL QUESTIONNAIRE

A summary was made of the international classification of impairments, which is a mixture of medical and surgical conditions, symptoms, and clinical signs. ${ }^{1}$ Clinical signs, rare items, and items related to the mentally handicapped, children, and the very elderly were excluded. Symptoms in the international classification of impairments are expressed in such technical language that they could not be incorporated into a questionnaire verbatim. Hannay ${ }^{15}$ has devised 44 general questions on symptoms which were designed to be mutually exclusive and to cover every possibility. The questions were phrased in simple non-technical language and these were matched with the corresponding item in the international classification of impairment. Because the interviews with the disabled adults from the Lambeth households were to be conducted by lay people, questions about sexual activity, homosexuality, alcoholism, and drug taking were excluded for fear of offending respondents and jeopardising the response to subsequent interviews.

Respondents were asked whether they suffered from each of the medical or surgical conditions and symptoms in turn. For each symptom respondents were asked whether it was being treated (with drugs or surgical appliances), whether it had been reported to a doctor, and whether a doctor had prescribed the treatment. Respondents were asked to show the interviewers all the medication they were taking. The interviewers wrote down the medication names from the label, and these were coded using a four digit code based on the pharmacological and general indices of Mimms. ${ }^{16}$ Respondents who had been to the doctor in the two weeks preceding the first interview were asked their reasons for consulting the doctor and the services the doctor provided.

The repeatability of the medical or surgical conditions and symptoms check lists over two days and two weeks was tested on patients aged 25 to 75 booked to attend outpatient clinics for the first time and who were classified as disabled using the original postal screening questionnaire. The repeatability of patients' statements about reporting of symptoms to doctors over two days, two weeks, and four weeks was tested after the patients had been to the clinic. The validity of the patients' statements about the conditions from which they believed they were suffering, the medication being taken, and the symptom they said had been reported to the doctor were checked by interviews with the clinic doctors.

DISABILITY QUESTIONNAIRE

This comprised 101 statements chosen from a validated health status measure. ${ }^{17}$ The statements were selected because they described the performance of an individual as distinct from medical or surgical conditions and symptoms. Nine areas of life were covered (see table 1). Severity weights are attached to each statement a respondent says applies to him or her because of ill-health. ${ }^{17}$

\section{STATISTICAL METHODS}

To identify the medical or surgical conditions and symptoms which contributed most to the overall level of disability in the community out of all medical or surgical conditions and symptoms respondents said they had, the total score (sum of severity weights) of individuals in each of the areas of life were regressed on all medical or surgical conditions and symptoms respondents had, controlling for age and sex, using the statistical package GLIM. A square root transformation of the category scores gave them an approximately normal distribution which was otherwise skewed towards the higher scores. 
The symptoms reported by the disabled respondents were initially classified as 'reported to a doctor and treated by him or her', 'reported to a doctor but untreated', 'not reported to a doctor but treated by respondents themselves', 'unreported and untreated', or 'absent'. However, it was not practicable to regress the disability scores on symptoms classified in five ways so the symptom regression analyses were repeated classifying symptoms firstly as 'treated' (by either doctor or respondent), 'untreated' or 'absent' and secondly as 'reported to a doctor' (whether treated by him or not), 'unreported to a doctor' or 'absent'. These two analyses allowed the relative contribution of, firstly, treated and untreated symptoms and, secondly, reported and unreported symptoms to the level of disability in Lambeth to be assessed.

\section{Results}

REPEATABILITY AND VALIDITY OF MEDICAL QUESTIONNAIRE

Complete sets of interviews were obtained with 117 outpatients. Allowing for symptoms which patients stated had resolved or appeared between the interviews, the repeatability of the medical or surgical conditions and symptoms check-lists over 24 hours and two weeks was satisfactory (percentage repeatability rarely less than $80 \%$ ). Clinic doctors corroborated patients' statements about their medical and surgical conditions, symptoms reported to doctors, and medication being taken (percentage of agreement rarely less than $80 \%$ ). After two weeks, recall of symptoms reported to the doctor was high (percentage of agreement also rarely less than $80 \%$ ).

RESPONSE

First interviews were obtained from $81 \%$ and second interviews from $68 \%$ of the 1100 adults aged 16 to 75 whom the screening questionnaires had identified as restricted in their lives because of illness. Statistically, the non-responders did not differ significantly from the responders on age, sex, and social class at screen, severity of disability (at first interview or number of items ticked on the screening questionnaire) or frequency of particular medical or surgical conditions (at first interview or on screening questionnaire).

REGRESSION OF DISABILITY ON MEDICAL OR SURGICAL CONDITIONS AND SYMPTOMS

Table 1 shows the medical or surgical conditions and table 2 the symptoms that were significantly associated $(p<0.05)$ with restriction of the sample's performance in different areas of life when the disability scores were regressed on all conditions and symptoms of which the disabled complained. The regression coefficients represent the increase in a category score associated with the presence of each medical or surgical condition (or symptom), controlling for the presence or absence of other conditions (or symptoms). In most cases the symptoms can be matched to a particular medical or surgical condition. The letter(s) after a symptom in table 2 indicate the medical or surgical condition(s) in table 1 with which it can be matched.

FREQUENCY OF (i) UNREPORTED UNTREATED, (ii) SELF-MEDICATED, AND (iii) REPORTED BUT UNTREATED SYMPTOMS AMONG THE DISABLED Table 3 shows the symptoms most frequently mentioned by the disabled as being neither reported to a doctor nor treated by the respondents themselves. The only symptoms not reported to a doctor which were being treated by the disabled themselves that were mentioned by $5 \%$ or more of respondents in any age group were dry cough or sore throat; headaches; toothache, pain in jaw or sore gums; and constipation. Table 4 shows the symptoms

Table 1 Regression coefficients of conditions associated with different categories of disability

\begin{tabular}{|c|c|c|c|c|c|c|c|c|c|}
\hline $\begin{array}{l}\text { Disease or } \\
\text { Disorder }\end{array}$ & Communication & $\begin{array}{l}\text { Eating and } \\
\text { drinking }\end{array}$ & $\begin{array}{l}\text { Bodycare and } \\
\text { movement } \\
\text { of limbs }\end{array}$ & Ambulation & Mobility & $\begin{array}{l}\text { Household } \\
\text { management }\end{array}$ & Rest & $\begin{array}{l}\text { Recreation } \\
\text { and pastime }\end{array}$ & $\begin{array}{l}\text { Social } \\
\text { interaction }\end{array}$ \\
\hline Depression (a) & 0.83 & 0.47 & 0.07 & 0.95 & $1 \cdot 85$ & $1 \cdot 11$ & 1.99 & 1.60 & 0.07 \\
\hline Stroke (b) & $1 \cdot 71$ & $0 \cdot 69$ & 0.07 & 1.88 & $2 \cdot 07$ & 1.85 & $1 \cdot 16$ & 2.07 & 0.07 \\
\hline Arthritis (c) & & & 0.07 & 0.60 & 0.52 & 1.46 & & & 0.07 \\
\hline Sciatica (d) & & & 0.06 & & & & 0.63 & 0.76 & 0.06 \\
\hline Foot trouble (e) & & & & 0.56 & 0.68 & & $0 \cdot 83$ & $1 \cdot 22$ & 0.06 \\
\hline Hypertension (f) & & 0.60 & & & & & 0.69 & 0.88 & \\
\hline Heart trouble $(\mathrm{g})$ & & 0.46 & & & & & & & \\
\hline Bronchitis (h) & & & & 0.51 & & & & & \\
\hline Asthma (i) & & & & & & & & 1.09 & \\
\hline Diabetes (j) & & 1.46 & & & & & & & \\
\hline Cataracts (k) & 1.68 & & & & & & & & \\
\hline Haemorrhoids (l) & & 0.46 & & & & & & 0.92 & \\
\hline
\end{tabular}

$\mathrm{N}=692$.

Only statistically significant regression coefficients $(p<0.05)$ are shown. 
Table 2 Regression coefficients of symptoms associated with different categories of disability

\begin{tabular}{|c|c|c|c|c|c|c|c|c|c|}
\hline Symptom & Communication & $\begin{array}{l}\text { Eating and } \\
\text { drinking }\end{array}$ & $\begin{array}{l}\text { Bodycare and } \\
\text { movement } \\
\text { of limbs }\end{array}$ & Ambulation & Mobility & $\begin{array}{l}\text { Household } \\
\text { management }\end{array}$ & Rest & $\begin{array}{l}\text { Recreation } \\
\text { and pastime }\end{array}$ & $\begin{array}{l}\text { Social } \\
\text { interaction }\end{array}$ \\
\hline \multicolumn{10}{|l|}{$\begin{array}{l}\text { Difficulty getting } \\
\text { to sleep or staying } \\
\text { asleep (a) }\end{array}$} \\
\hline $\begin{array}{r}\text { Difficulty keeping } \\
\text { balance on feet }\end{array}$ & & & & & & & & & \\
\hline $\begin{array}{l}(\mathrm{a}, \mathrm{b}) \\
\text { General tiredness }\end{array}$ & & & $0 \cdot 14$ & 1.67 & 0.99 & $1 \cdot 48$ & 0.76 & $1 \cdot 36$ & 0.76 \\
\hline or weakness (a) & & & & & 0.62 & 0.59 & $1 \cdot 32$ & $1 \cdot 16$ & 0.81 \\
\hline $\begin{array}{l}\text { Trouble learning, } \\
\text { remembering or } \\
\text { thinking clearly }\end{array}$ & & & & & & & & & \\
\hline $\begin{array}{l}\text { (a) } \\
\text { Limbs paralysed, } \\
\text { deformed, missing }\end{array}$ & $2 \cdot 21$ & & & & & 0.73 & 0.75 & $1 \cdot 25$ & 0.89 \\
\hline $\begin{array}{l}\text { or broken (b) } \\
\text { Pain or stiffness in } \\
\text { joints or back }\end{array}$ & $1 \cdot 28$ & $1 \cdot 00$ & $1 \cdot 00$ & 0.89 & $1 \cdot 25$ & $1 \cdot 36$ & $1 \cdot 10$ & 1.07 & 0.83 \\
\hline$(\mathbf{c}, \mathbf{d})$ & & & 0.05 & 0.57 & $0 \cdot 83$ & $1 \cdot 01$ & 1.06 & 0.99 & $0 \cdot 75$ \\
\hline $\begin{array}{l}\text { Swelling of feet or } \\
\text { ankles }(e, g)\end{array}$ & & & & 1.09 & 0.63 & & 1.02 & 0.74 & 0.51 \\
\hline $\begin{array}{l}\text { Shortness of breath } \\
(\mathrm{g}, \mathrm{h}, \mathrm{i})\end{array}$ & & $0 \cdot 37$ & & 0.51 & & & & 0.45 & \\
\hline $\begin{array}{l}\text { Trouble seeing, } \\
\text { hearing or talking } \\
\text { (k) }\end{array}$ & 1.91 & & & & & & & & \\
\hline Constipation (l) & & $1 \cdot 57$ & & & & & & $0 \cdot 75$ & \\
\hline $\begin{array}{l}\text { Loss of appetite or } \\
\text { weight }\end{array}$ & & $1 \cdot 24$ & & & & & & & \\
\hline $\begin{array}{l}\text { Pain in stomach } \\
\text { (between meals/ } \\
\text { nightly) } \\
\text { Pain in calves }\end{array}$ & & & & & & & & $\begin{array}{l}0.96 \\
5.43\end{array}$ & \\
\hline $\begin{array}{ll}\text { Frequency } & \text { or } \\
\text { incontinence } & \text { of } \\
\text { urine } & \end{array}$ & & & 0.09 & 0.69 & 0.98 & & $0 \cdot 74$ & 0.91 & 0.72 \\
\hline
\end{tabular}

$\mathrm{N}=692$.

Only statistically significant regression coefficients $(p<0.05)$ are shown.

Table 3 Symptoms which respondents had not reported to doctors and which were untreated*

\begin{tabular}{|c|c|c|c|c|c|c|}
\hline \multirow[b]{2}{*}{ Symptom } & \multicolumn{3}{|l|}{ Men } & \multicolumn{3}{|c|}{ Women } \\
\hline & $\begin{array}{l}25-44 \\
(\%)\end{array}$ & $\begin{array}{l}45-64 \\
(\%)\end{array}$ & $\begin{array}{l}65-75 \\
(\%)\end{array}$ & $\begin{array}{l}25-44 \\
(\%)\end{array}$ & $\begin{array}{l}45-64 \\
(\%)\end{array}$ & $\begin{array}{l}65-75 \\
(\%)\end{array}$ \\
\hline Difficulty sleeping & 9 & 11 & 11 & 16 & 16 & 16 \\
\hline $\begin{array}{l}\text { General tiredness or } \\
\text { weakness }\end{array}$ & 18 & 6 & 10 & 15 & 19 & 16 \\
\hline $\begin{array}{l}\text { Spells of being upset, } \\
\text { depressed or crying }\end{array}$ & 14 & 7 & 7 & 20 & 14 & 14 \\
\hline Spells of giddiness & 5 & 4 & 10 & & & \\
\hline $\begin{array}{l}\text { Dry cough or sore throat } \\
\text { Trouble learning, } \\
\text { remembering or thinking }\end{array}$ & & & & 19 & 16 & 14 \\
\hline clearly & & & & 3 & 11 & 14 \\
\hline Swelling of feet or ankles & & & & 7 & 14 & 12 \\
\hline Overweight & 0 & 13 & 5 & 23 & 14 & 12 \\
\hline Ringing in ears & & & & 8 & 9 & 11 \\
\hline Difficulty seeing & & & & 5 & 8 & 10 \\
\hline Pain in joints & & & & 8 & 17 & 10 \\
\hline Headaches & & & & 15 & 12 & 8 \\
\hline $\begin{array}{l}\text { Spells of feeling hot, } \\
\text { nervous or shaky }\end{array}$ & & & & 12 & 18 & 6 \\
\hline Pain in eye & & & & 10 & 5 & 5 \\
\hline Loss of appetite & & & & 7 & 12 & 4 \\
\hline Pain or stiffness in back & & & & 11 & 7 & 3 \\
\hline $\mathbf{N}$ & 76 & 187 & 138 & 45 & 164 & 94 \\
\hline
\end{tabular}

*For each sex, only symptoms reported by more than $10 \%$ of respondents in one or more of the three age groups are shown. which the disabled had reported to their doctors but for which he/she chose not to prescribe medication, surgical appliances or aids.

REGRESS I O N OF D ISA B ILITY O N REPORTED/UNREPORTED SYMPTOMS

When the disability scores were regressed on symptoms classified as 'reported to a doctor', 'not reported to a doctor', or 'absent', it was mainly reported symptoms that were significantly associated with disability. Only seven symptoms unreported to doctors were significantly associated with disability. Unreported spells of feeling hot, nervous or shaky were significantly associated $(\mathrm{p}<0.05)$ with being restricted in body care, walking, and daytime rests and almost significantly $(\mathrm{p}<0 \cdot 10)$ with restriction in getting about the house and visiting friends. Unreported spells of giddiness were significantly associated with being restricted in body care and almost significantly with restriction in getting about the house and visiting friends. Unreported diarrhoea or vomiting was significantly associated with being restricted in housework and visiting friends and almost significantly with restriction in walking and 
Table 4 Symptoms reported to a doctor but untreated ${ }^{*}$

\begin{tabular}{|c|c|c|c|c|c|c|}
\hline \multirow[b]{2}{*}{ Symptom } & \multicolumn{3}{|l|}{ Men } & \multicolumn{3}{|l|}{ Women } \\
\hline & $\begin{array}{l}25-44 \\
(\%)\end{array}$ & $\begin{array}{l}45-64 . \\
(\%)\end{array}$ & $\begin{array}{l}65-75 \\
(\%)\end{array}$ & $\begin{array}{l}25-44 \\
(\%)\end{array}$ & $\begin{array}{l}45-64 \\
(\%)\end{array}$ & $\begin{array}{l}65-75 \\
(\%)\end{array}$ \\
\hline $\begin{array}{l}\text { Pain in joints } \\
\text { Difficulty keeping balance }\end{array}$ & 9 & 10 & 16 & 22 & 10 & 11 \\
\hline $\begin{array}{l}\text { on feet } \\
\text { Limbs paralysed, weak }\end{array}$ & 9 & 7 & 11 & 7 & 7 & 11 \\
\hline $\begin{array}{l}\text { or numb } \\
\text { General tiredness or }\end{array}$ & 11 & 11 & 10 & & & \\
\hline weakness & 5 & 10 & 9 & 18 & 13 & 17 \\
\hline Stiffness in joints & 7 & 12 & 9 & 14 & 7 & 8 \\
\hline Overweight & 14 & 13 & 7 & 16 & 15 & 1 \\
\hline Trouble seeing & & & & 5 & 4 & 12 \\
\hline Difficulty sleeping & & & & 4 & 6 & 10 \\
\hline Swelling of feet or ankles & & & & 11 & 10 & 9 \\
\hline Spells of giddiness & & & & 8 & 10 & 8 \\
\hline $\begin{array}{l}\text { Pain or stiffness in back } \\
\text { Spells of feeling hot, }\end{array}$ & & & & 16 & 7 & 8 \\
\hline nervous or shaky & & & & 3 & 10 & 3 \\
\hline $\mathbf{N}$ & 76 & 187 & 138 & 45 & 164 & 94 \\
\hline
\end{tabular}

*For each sex, only symptoms reported by more than $10 \%$ of respondents in one or more of the three age groups are shown.

body care. Unreported shortness of breath and trouble with periods or the menopause were significantly associated with being restricted in body care and daytime rests respectively. Unreported stomach pains and straining or unusual delay in urination were almost significantly associated with restriction in body care and recreation respectively.

REGRESSION OF DISABILITY O N TREATED/UNTREATED SYMPTOMS

When the disability scores were regressed on symptoms classified as 'treated' (whether by a doctor or the respondent), 'untreated', or 'absent', it was mainly treated symptoms that were significantly associated with disability. Only four untreated symptoms (reported and unreported to a doctor) were significantly associated with disability. Untreated constipation was significantly associated $(p<0.05)$ with being restricted in body care, getting around the house and outside, and daytime rests. Untreated spells of giddiness were significantly associated with restriction in housework and almost significantly $(\mathrm{p}<0 \cdot 10)$ with restriction in visiting friends. Untreated shortness of breath and straining or unusual delay in urination were significantly associated with restriction in body care.

CONTRIBUTIONS OF UNREPORTED AND UNTREATED SYMPTOMS TO LEVEL OF DISABILITY IN THE COMMUNITY

Symptoms that had been reported to a doctor or were being treated explained between 25 and $40 \%$ of the variance in disability in the different areas of life. Symptoms unreported to doctors or untreated added less than $0 \cdot 1 \%$ to the amount of variance explained.
SYMPTOMS AND DRUGS

There was reason to believe that iatrogenic symptoms might be common among disabled people in Lambeth. As many as $80 \%$ of the patient-initiated consultations with general practitioners in the fortnight preceding the first interview resulted in a prescription. Only $25 \%$ of the respondents were not taking any drugs, $16 \%$ were taking four or more drugs, and some were taking as many as 11 different drugs. In the two weeks preceding the interview, half as many respondents went to the surgery to collect a repeat prescription without actually talking to their doctors as went to consult them in person.

Drugs most commonly taken by the sample of 692 disabled were analgesics (36\%), hypnotics $(25 \%)$, diuretics $(21 \%)$, sedative/tranquillisers $(15 \%)$, and antidepressants (7\%). Some of the symptoms that had been found to be associated with restricted performance in the different areas of life can be caused or aggravated by these drugs (table 5). Table 6 shows the proportion of respondents with and without these disabling symptoms taking drugs which can cause or aggravate them.

Analgesics were taken significantly more frequently by respondents complaining of stomach pain between meals or disturbing sleep at night, constipation, and spells of giddiness than by respondents without those symptoms. Antidepressants were taken more frequently by respondents complaining of straining or unusual delay in urination and diuretics more frequently by those complaining of difficulty in sleeping.

Some of the psychological symptoms could be the effects of "depression" or psychotropic drugs. Sedatives were taken more frequently by respondents complaining of difficulty in keeping balance on feet, general tiredness or weakness and trouble in learning, remembering or thinking clearly

Table 5 Possible relation between disabling symptoms and drugs being taken by disabled people in Lambeth

\begin{tabular}{|c|c|}
\hline Disabling symptom & $\begin{array}{l}\text { Drugs that could } \\
\text { cause symptom }\end{array}$ \\
\hline $\begin{array}{l}\text { Difficulty getting to sleep or staying asleep at night } \\
\text { Difficulty keeping balance on feet } \\
\text { General tiredness or weakness } \\
\text { Trouble learning, remembering or thinking clearly } \\
\text { Limbs paralysed, deformed, missing or broken } \\
\text { Pain or stiffness in joints or back } \\
\text { Swelling of feet or ankles } \\
\text { Shortness of breath } \\
\text { Trouble seeing, hearing or talking }\end{array}$ & $\begin{array}{l}\text { Diuretics } \\
\text { Sedatives } \\
\text { Diuretics } \\
\text { Sedatives }\end{array}$ \\
\hline $\begin{array}{l}\text { Constipation } \\
\text { Loss of appetite or weight }\end{array}$ & Analgesics \\
\hline $\begin{array}{l}\text { Pain in stomach between meals or nightly } \\
\text { Pain in calves }\end{array}$ & Analgesics \\
\hline $\begin{array}{l}\text { Frequency or incontinence of urine } \\
\text { Spells of feeling hot, nervous or shaky }\end{array}$ & Diuretics \\
\hline Spells of giddiness & $\begin{array}{l}\text { Analgesics, } \\
\text { antidepressants }\end{array}$ \\
\hline
\end{tabular}


Table 6 Proportion of patients with and without disabling symptoms taking possible offending drug

\begin{tabular}{|c|c|c|c|c|}
\hline \multirow[b]{2}{*}{ Symptom } & \multirow[b]{2}{*}{ Drug } & \multicolumn{3}{|c|}{ Number of patients taking drug } \\
\hline & & With symptom & Without symptom & $x^{2}$ \\
\hline Difficulty getting to sleep or staying asleep & Diuretic & $64 / 254$ & $78 / 435$ & $5.17 p<0.025$ \\
\hline \multirow{2}{*}{ Difficulty keeping balance on feet } & Sedatives & $36 / 95$ & $66 / 596$ & $46.85 p<0.001$ \\
\hline & Hypnotics & $33 / 95$ & $138 / 596$ & $5.90 p<0.025$ \\
\hline \multirow{3}{*}{$\begin{array}{l}\text { General tiredness or weakness } \\
\text { Trouble learning, remembering or thinking clearly }\end{array}$} & Sedatives & $50 / 249$ & $52 / 437$ & $8.39 \mathrm{p}<0.025$ \\
\hline & Sedatives & $24 / 113$ & $78 / 579$ & $4.54 \mathrm{p}<0.05$ \\
\hline & Antidepressants & $20 / 113$ & $31 / 579$ & $21 \cdot 11 \mathrm{p}<0.001$ \\
\hline \multirow{4}{*}{$\begin{array}{l}\text { Constipation } \\
\text { Stomach pain between meals or disturbing sleep } \\
\text { Spells of giddiness }\end{array}$} & Analgesics & $51 / 105$ & $199 / 587$ & $8.31 \mathrm{p}<0.01$ \\
\hline & Analgesics & $34 / 62$ & $216 / 630$ & $10.33 p<0.01$ \\
\hline & Antidepressants & $21 / 45$ & $30 / 546$ & $13.54 \mathrm{p}<0.001$ \\
\hline & Analgesics & $70 / 45$ & $179 / 546$ & $10.33 \mathrm{p}<0.01$ \\
\hline
\end{tabular}

$\mathrm{N}=692$ difference between $\mathrm{N}$ and sum of denominators due to missing data.

than by respondents without those symptoms. Antidepressants were taken more frequently by those complaining of spells of giddiness and trouble in learning, remembering or thinking clearly, and hypnotics by those complaining of difficulty in keeping balance on the feet.

\section{Discussion}

There were many symptoms which respondents in the Lambeth study had not told their doctors about and which were not being treated. Surveys of elderly people living at home, many of whom are disabled, have drawn attention to the frequency of symptoms which elderly people have not told their general practitioners about and which are untreated (for references see 10). The frequency of unreported, untreated symptoms among the middle aged (45-64) and younger physically disabled in Lambeth was similar to that among the over $65 \mathrm{~s}$ and suggests that unreported, untreated symptoms should receive as much consideration in a study of disability among 25-75 year olds as in a study of disability among the elderly. Not all symptoms which respondents had reported to their doctors were being treated. Reported but untreated symptoms were sufficiently common to suggest that as much consideration should be given to these symptoms as to symptoms which have not been reported to a doctor at all. The frequency of self-medication among the disabled was less than has been found in surveys of the general population. ${ }^{4-6}$

It was impractical to perform multiple regression analysis using the symptoms coded in five ways: being treated by a doctor, reported to a doctor but untreated, not reported to a doctor but being treated by the respondent, neither reported to a doctor nor being treated, or absent. Therefore, disability had to be regressed on symptoms coded, firstly, as reported, not reported to a doctor, or absent, and, secondly, as treated, untreated, or absent. Despite finding that unreported and/or untreated symptoms were common, the regression analyses showed that only three untreated symptoms (constipation, giddiness, shortness of breath) and four unreported symptoms (shortness of breath, giddiness, diarrhoea/vomiting, feeling hot, nervous, or shaky) were associated with disability. There have not been any previous studies of the frequency and significance of unreported and/or untreated symptoms among the disabled so the only surveys with which our findings can be compared are the screening studies of the elderly, many of whom are disabled. Although, Lowther $e_{0}{ }_{\Omega}$ $a l^{19}$ found on follow-up 18 to 30 months aftero screening that $23 \%$ of elderly patients were "helped by early diagnosis", and Williams ${ }^{19}$ reported ao comparable benefit in $27 \%$, a randomised controlled trial was needed to evaluate the benefit of identifying unreported, untreated health problems. $A^{\text {. }}$ randomised controlled trial of geriatric screening was undertaken over a two-year period by Tulloch and Moore. ${ }^{10}$ In the screened group, 380 medical conditions were reported, $144(38 \%)$ of which were previously undetected. However, independent assessment of patients in the study and control groups at the end of the two-year period showed that the screening programme had made no significant impact on disability. The results of the trial suggest that few of the unreported, untreated symptoms were associated with disability.

There was circumstantial evidence that iatrogenic symptoms would be common in Lambeth, and it was observed that some of the disabling symptoms could be the effects, mainly adverse, of the drugs being taken most frequently. A "possible adverse drug reaction" has been defined as one that is known to occur but, firstly, the temporal relation is unclear and, secondly, other causes are possible. ${ }^{20}$ Information about when the respondents started taking the suspected drugs and when they developed the relevant symptoms was not collected during the Lambeth survey. Moreover, it was difficult except in a few cases discussed below to exclude other explanations for the relation between symptoms and 
drugs. Therefore it was impossible to do more than identify restrictions in life which might possibly be the effects, mainly adverse, of drugs.

The association between diuretics and difficulty in sleeping could mean that respondents had to awaken during the night to pass urine or that respondents had difficulty in getting to sleep because of orthopnoea for which they were taking diuretics. Against this latter explanation is that shortness of breath was not significantly more frequent among respondents with difficulty in sleeping who were taking diuretics than among those not taking diuretics. Therefore, it is likely to be the diuretics that were disturbing sleep.

In Lambeth, difficulty in getting to sleep or staying asleep at night and frequency or incontinence of urine were associated with restriction in many areas of life. It was possible that these symptoms were the physiological effects of diuretics, and many of the hypertensive respondents were taking diuretics. Bulpitt and Dollery, ${ }^{21}$ using a self-administered symptom questionnaire, found that between 33 and $57 \%$ of patients being treated at a hypertensive clinic with diuretics alone and in combination with other drugs complained of "sleeplessness", and other symptoms were common.

If the reported psychological symptoms were the consequence of psychotropic drugs rather than "depression", the symptoms should be more frequent among respondents with treated depression than among those with untreated depression. However, there was no significant difference in the frequency of difficulty in keeping balance on the feet; general tiredness or weakness; and trouble in learning, remembering, or thinking clearly among respondents with depression who were taking sedatives and those not taking sedatives. Similarly, there was no significant difference in the frequency of giddiness among respondents with depression taking and not taking antidepressants.

There does not appear to be much scope for reducing the level of disability among 25-75 year olds living at home by increasing general practitioners' awareness of unreported and untreated symptoms. Whether removing the iatrogenic component of disability would reduce the level of disability in the community depends on how disabled respondents would be if those drugs were withdrawn or substituted. We have circumstantial evidence that some drugs might be beneficially substituted. Firstly, prescribing was almost the only service general practitioners provided, and many patients obtained repeat prescriptions without talking to the doctor. This suggests that patients' drug regimens might not be regularly reviewed. Secondly, diuretics were commonly prescribed for hypertension without cardiac disease. Moreover, the most frequently prescribed diuretic was frusemide, whereas patients might need only a milder diuretic. Thirdly, a number of patients were taking two, and some three, analgesics, and the most frequently taken analgesic was non-enteric coated aspirin.

We thank Professor RF Heller and Professor WW Holland for their advice and criticism, Dr DL Patrick for allowing us to incorporate the medical questionnaire into the second interview with the disabled adults, and Mrs Linda Clarke for word processing the manuscript. The paper is based on a thesis for which Dr Hedley Peach was awarded the $\mathrm{PhD}$ by the University of London. The study was funded by the Department of Health and Social Security.

\section{References}

${ }^{1}$ World Health Organization. International classification of impairments, disabilities and handicaps. Geneva: World Health Organization, 1980.

${ }^{2}$ Stocks P. Sickness in the population of England and Wales in 1944-7. General Register Office Studies on Medical and Population Subjects Number 2. London: HMSO, 1949.

${ }^{3}$ Horder J, Horder E. Illness in general practice. Practitioner 1954; 173: 177-87.

${ }^{4}$ Wadsworth MEJ, Butterfield WJM, Blaney R. Health and sickness: the choice of treatment. Tavistock: London, 1971.

${ }^{5}$ Dunnell K, Cartwright A. Medicine takers, prescribers and hoarders. London and Boston: Routledge and Kegan Paul, 1972.

${ }^{6}$ Jefferys M, Brotherson JHF, Cartwright A. Consumption of medicines on a working-class housing estate. Br J Prev Soc Med 1960; 14: 64-76.

${ }^{7}$ Beresford SAA, Waller JJ, Banks MH, Wale CJ. Why do women consult doctors? Social factors and the use of the general practitioner. Br J Prev Soc Med 1977; 31: 220-6.

${ }^{8}$ Patrick DL, Darby SC, Green S, Horton G, Locker D, Wiggins RD. Screening for disability in the inner city. $J$ Epidemiol Community Health 1981; 35: 65-70.

${ }^{9}$ Harris AI. Handicapped and impaired in Great Britain. London: HMSO, 1971.

${ }^{10}$ Tulloch AJ, Moore V. A randomized controlled trial of geriatric screening in general practice. J Roy Coll Gen Pract 1979; 29: 733-42.

${ }^{11}$ Thompson M, Anderson M, Wood PHN. Locomotor disability-a study of need in an urban community. Br J Prev Soc Med 1974; 28: 70.

${ }^{12}$ Hopkins A, Scambler S. How doctors deal with epilepsy. Lancet 1977; i: 183-6.

${ }^{13}$ Johnson GS, Johnson RH. Social services support for multiple sclerosis patients in west of Scotland. Lancet 1977; i: $31-4$

${ }^{14}$ Patrick DL, Peach H, Gregg I. Disablement and care: a comparison of patient views and general practitioner knowledge. J Roy Coll Gen Pract 1982; 32: 429-43.

${ }^{15}$ Hannay DR. Symptom prevalence in the community. $J$ Roy Coll Gen Pract 1978; 28: 429-89. 
${ }^{16}$ Duncan C. Monthly index of medical specialties Vol. 21, No. 9. Duncan C, ed. London: Haymarket Publishing Ltd, 1979.

${ }^{17}$ Bergner M, Bobbitt RA, Carter WB, Gibson BS. The Sickness Impact Profile: development and final revision of a health status measure. Med Care 1981; 19: 789-805.

${ }^{18}$ Lowther CP, MacCleod RDM, Williamson J. Evaluation of early diagnostic services for the elderly. $\mathrm{Br}$ Med J 1970; 3: 275-7.
${ }^{19}$ Williamson J, Stokoe IH, Gray S, Fisher M, Smith A, McGhee A, Stephenson E. Old people at home. Their unreported needs. Lancet 1964; i: 1117-20.

${ }^{20}$ Seidl LG, Thorton GF, Cluff LE. Epidemiological studies of adverse drug reactions. Am J Publ Health 1965; 55: 1170-8.

${ }^{21}$ Bulpitt CJ, Dollery CT. Side effects of hypotensive agents evaluated by a self-administered questionnaire. $\mathrm{Br} \mathrm{Med}$ J 1973; 3: 485-96. 